\title{
New Azomethine Compounds on the Basis $m$-Phenylenediamine and Substituted Benzaldehydes Capable of Oxidative Polymerization
}

\author{
T. A. Borukaev1*, A. M. Mazloeva1, R. M. Otarova1, Yu. A. Malkanduev1, A. Kh. Malamatov1, \\ A. V. Orlov \\ ${ }^{1}$ Kabardino-Balkar State University (Named after H. M. Berbekov), Nalchik, Russia \\ ${ }^{2}$ A.V.Topchiev Institute of Petrochemical Synthesis, Russian Academy of Sciences, Moscow, Russia \\ Email: *boruk-chemical@mail.ru
}

How to cite this paper: Borukaev, T.A., Mazloeva, A.M., Otarova, R.M., Malkanduev, Yu.A., Malamatov, A.Kh. and Orlov, A.V. (2018) New Azomethine Compounds on the Basis $m$-Phenylenediamine and Substituted Benzaldehydes Capable of Oxidative Polymerization. Open Journal of Polymer Chemistry, 8, 34-39.

https://doi.org/10.4236/ojpchem.2018.82004

Received: March 2, 2018

Accepted: May 28, 2018

Published: May 31, 2018

Copyright $\odot 2018$ by authors and Scientific Research Publishing Inc. This work is licensed under the Creative Commons Attribution International License (CC BY 4.0).

http://creativecommons.org/licenses/by/4.0/

\begin{abstract}
Low-temperature condensation of $m$-phenylene diamine and various aromatic aldehydes (benzaldehyde, $m$-, $o$-nitrobenzaldehyde, $p$-diethylaminobenzaldehyde, $o-, p$-hydroxybenzaldehyde and 4-hydroxy-3,5-ditert-butylbenzaldehyde) in the ethyl alcohol medium synthesized new azomethine compounds. With the help of spectral methods and elemental analysis, the structure of the azomethine compounds obtained was confirmed. It was founded that irradiation of azomethine compounds with UV light at a wavelength of $300-330 \mathrm{~nm}$ results in their emission. The luminescent properties of the resulting compounds are due to the presence of chromophore azomethine groups in the molecule structure. In particular, the $\pi$-electrons of the azomethine bonds can undergo irradiation to a different energy levels, accompanied by fluorescence. It was shown that synthesized azomethine compounds are capable of oxidative polymerization. Based on azomethine compounds in hydrochloric acid solution synthesized polymers with conjugated bonds, which had low molecular-mass characteristics. It is shown that the oxidative polymerization of azomethines proceeds through a slow (one-electron transfer) and rapid (recombination of the radical cations) stage.
\end{abstract}

\section{Keywords}

Azomethine Compounds, Synthesis, Luminescence, Oxidative Polymerization

\section{Introduction}

Recently, the interest of researchers has attracted compounds with conjugated 
bonds, in particular, azomethine compounds. This is due to the complex of properties that these compounds possess [1]. At the same time, the importance and prospects of the use of azomethines in various fields of science and technology [2] [3] [4] [5] demonstrates that the potential of this class of compounds is far from exhausted. Therefore, the search for new structures of azomethines having special properties (luminescence, electrical conductivity, solubility) seems very promising and relevant.

The purpose of this work is the synthesis of new azomethines based on $m$-phenylene diamine and various substituted benzaldehydes, capable of oxidative polymerization. Benzaldehyde, $m$-, $o$-nitrobenzaldehyde, $p$-diethylaminobenz-aldehyde, $o$-, $p$-hydroxybenzaldehyde and 4-hydroxy-3,5-ditertbutyl-benzaldehyde were used as substituted benzaldehydes.

Synthesis of azomethines was carried out at a temperature of $20^{\circ} \mathrm{C}-40^{\circ} \mathrm{C}$ in ethanol medium at a stoichiometric ratio (1,1 mole diamine and 1 mole aldehyde), reaction time $1.5-2 \mathrm{~h}$. The reaction schemes for the synthesis of azomethines can be represented as follows:

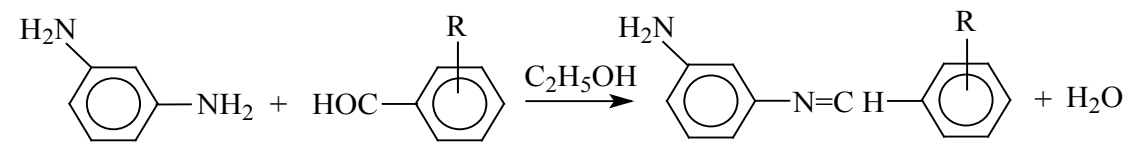

$$
\mathrm{R}=\mathrm{H}(\mathrm{I}) ; o-\mathrm{OH}(\mathrm{II}) ; p-\mathrm{OH}(\mathrm{III}) ; m-\mathrm{NO}_{2}(\mathrm{IV}) ; o-\mathrm{NO}_{2}(\mathrm{~V}) ; p-\mathrm{N}\left(\mathrm{C}_{2} \mathrm{H}_{5}\right)_{2}(\mathrm{VI}) ;
$$
and

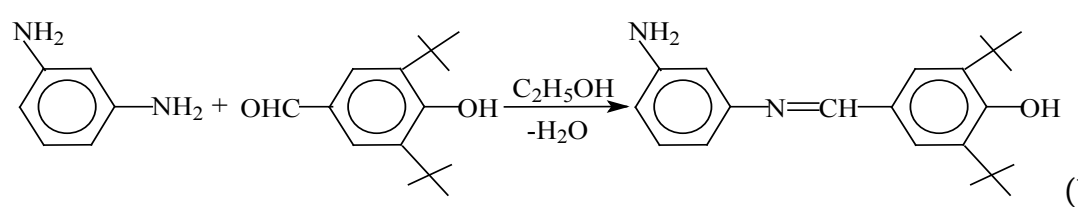

Synthesized azomethines were crystalline substances from yellow to orange, fusible and soluble in organic solvents (dichloroethane, acetone, dimethylacetamide, etc.).

To prepare the azomethines (I, II), $51.0 \mathrm{mmol}$ of $m$-phenylenediamine was charged into a two-necked flask and $60 \mathrm{ml}$ of ethanol was added and the diamine was dissolved. $47.0 \mathrm{mmol}$ of benzaldehyde (o-hydroxybenzaldehyde) was added dropwise to the solution, after which the reaction mixture was stained yellow (I) or light orange (II). The temperature of the reaction mixture rose to $40^{\circ} \mathrm{C}$. A precipitate formed from the reaction medium, which filtered off after 1 hour of stirring. The precipitate washed several times with alcohol and dried in vacuum at a temperature of no higher than $30^{\circ} \mathrm{C}$.

To prepare the azomethines (III-VII), $27.8 \mathrm{mmol}$ of $m$-phenylene diamine charged into a two-necked solution and $30 \mathrm{ml}$ of ethanol added and the diamine dissolved. A solution of $25.3 \mathrm{mmol}$ of substituted benzaldehyde in $30 \mathrm{ml}$ of ethanol added drop wise to the reaction medium. During the reaction, a precipitate formed from the solution. The reaction mixture stirred for an additional 1.5 
hours. The precipitate filtered off, washed with ethanol, and dried in vacuum at room temperature.

The IR spectra of the compounds recorded on a SHIMADZU IR Fourier spectrometer in the range $400-4000 \mathrm{~cm}^{-1}$. Samples were prepared in the form of tablets compressed with $\mathrm{KBr}$. The NMR spectra $\left({ }^{1} \mathrm{H}-300 \mathrm{MHz}, \mathrm{DMSO}\right)$ recorded on an MSL-300 instrument. The evaluation of luminescent properties, synthesized substances, carried out in the DFS-24 (LOMO) spectrometer. The elemental analysis performed on the Elementar Vario EL-III CHNOS analyzer, the error of determination being $0.1 \%$.

The synthesized azomethines were powders from yellow to orange and yield $70 \%-85 \%$. The elemental composition of azomethines is close to the theoretical one. Melting temperature and spectral analysis of azomethines: I - m.p. $165^{\circ} \mathrm{C} \pm$ $1^{\circ} \mathrm{C}$. IR spectrum, $\mathrm{cm}^{-1}: 1615(-\mathrm{CH}=\mathrm{N}-), 3416\left(-\mathrm{NH}_{2}\right) .{ }^{1} \mathrm{H}$ NMR $\delta$, ppm: 8.3 $(-\mathrm{CH}=\mathrm{N}-), 6.5-8.0(\mathrm{Ar}), 3.5\left(-\mathrm{NH}_{2}\right) ; \mathrm{II}-$ m.p. $98^{\circ} \mathrm{C} \pm 1^{\circ} \mathrm{C}$. IR spectrum, $\mathrm{cm}^{-1}$ : $1606(-\mathrm{CH}=\mathrm{N}-), 3354\left(-\mathrm{NH}_{2}\right) .{ }^{1} \mathrm{H}$ NMR $\delta$, ppm: 8,4 (-CH = N-), $6.5-8.0(\mathrm{Ar})$, $3.5\left(-\mathrm{NH}_{2}\right), 5.5(-\mathrm{OH})$; III - m.p. $185^{\circ} \mathrm{C}-187^{\circ} \mathrm{C}$. IR spectrum, $\mathrm{cm}^{-1}: 1601(-\mathrm{CH}=$ $\mathrm{N}-), 3317-3400\left(-\mathrm{NH}_{2}\right) .{ }^{1} \mathrm{H}, \delta$ ppm: $8.5(-\mathrm{CH}=\mathrm{N}-), 6.6-8.0(\mathrm{Ar}) ; 3.6\left(-\mathrm{NH}_{2}\right)$, $5.5(-\mathrm{OH}) ; \mathrm{IV}-\mathrm{m} . \mathrm{p} .170^{\circ} \mathrm{C} \pm 1^{\circ} \mathrm{C}$. IR spectrum, $\mathrm{cm}^{-1}: 1625(-\mathrm{CH}=\mathrm{N}-), 3366$ $\left(-\mathrm{NH}_{2}\right), 1350\left(-\mathrm{NO}_{2}\right) .{ }^{1} \mathrm{H}$ NMR $\delta$, ppm: $8.4(-\mathrm{CH}=\mathrm{N}-), 6.5-8.0(\mathrm{Ar}), 3.6\left(-\mathrm{NH}_{2}\right)$; V is m.p. $73^{\circ} \mathrm{C} \pm 1^{\circ} \mathrm{C}$. IR spectrum, $\mathrm{cm}^{-1}: 1595(-\mathrm{CH}=\mathrm{N}-), 3374\left(-\mathrm{NH}_{2}\right), 1339$ $\left(-\mathrm{NO}_{2}\right) .{ }^{1} \mathrm{H}, \delta$, ppm: $8.45(-\mathrm{CH}=\mathrm{N}-), 6.4-8.2(\mathrm{Ar}), 3.55\left(-\mathrm{NH}_{2}\right)$; VI - m.p. $165^{\circ} \mathrm{C}$ $\pm 1^{\circ} \mathrm{C}$. IR spectrum, $\mathrm{cm}^{-1}: 1604(-\mathrm{CH}=\mathrm{N}-), 3384\left(-\mathrm{NH}_{2}\right), 1077-1229\left(-\mathrm{NEt}_{2}\right)$. ${ }^{1} \mathrm{H}$ NMR $\delta$, ppm: $8.4(-\mathrm{CH}=\mathrm{N}-), 6.5-7.9(\mathrm{Ar}), 3.5\left(-\mathrm{NH}_{2}\right), 1.5-2.1\left(-\mathrm{CH}_{2}\right.$, $\left.-\mathrm{CH}_{3}\right)$; VII - Ex. $320^{\circ} \mathrm{C}$. IR spectrum, $\mathrm{cm}^{-1}: 1624(-\mathrm{CH}=\mathrm{N}-), 3424\left(-\mathrm{NH}_{2}\right) .{ }^{1} \mathrm{H}$ NMR $\delta$, ppm: $8.3(-\mathrm{CH}=\mathrm{N}-), 6.6-8.2(\mathrm{Ar}), 3.5\left(-\mathrm{NH}_{2}\right), 5.5(-\mathrm{OH}), 1.6-2.3$ (t-butyl).

The introduction of aldehydes into the reaction medium determined by their agregate state. Thus, if the aldehyde is in a liquid state at room temperature, then it is added drop wise to the reaction medium; if the aldehyde is a solid, then it must be dissolved in a certain part of the ethyl alcohol and only then added to the reaction medium drop by drop [6].

It is know that compounds containing azomethine groups have luminescent properties. In this connection, it was of interest to study the luminescent properties of the compounds obtained. Studies have shown that when excitation of the azomethine compounds obtained by UV light with a wavelength of $330 \mathrm{~nm}$, their intense emission is observed, i.e. the compounds exhibit luminescent properties ( $\lambda$ lumin $=380-580 \mathrm{~nm}$.). In this case, the quantum yields are characterize by the values $0.2-0.38$. This behavior of the azomethine compounds obtained is due to the presence in the structures of the active $\pi$-system and the chromophore group $-\mathrm{CH}=\mathrm{N}$-. Obviously, irradiation of these compounds with UV light leads to the excitation of $\pi$-electrons of the conjugated system of the azomethine bond, which transfer to another energy level, accompanied by intense fluorescence. It was found that the intensity of luminescence and the wavelength of the luminescence of chromophore groups depend on the geometric 
features of the system of $\pi$-electrons. In turn, the geometric length or dimension of the active $\pi$-system will depend on the chemical structure of the original substituted benzaldehyde used in the synthesis of azomethine compounds, i.e. from the type of substituents in benzaldehyde that participate in the system of conjugation of the entire molecule of azomethine. Thus, azomethine compounds obtained on the basis of benzaldehyde with donor-acceptor substituents in the para- position have a more intense luminescence, due to a significant asymmetry of the electronic system.

It should be noted that synthesized azomethine compounds can be used as monomers for the synthesis of luminescent polyconjugated polymers. The presence of a free amino group and the absence of various substituents with respect to it in the para-position makes it possible to use them as promising materials for oxidative polymerization. In this connection, in the present work, polymers with conjugated double bonds were obtained by oxidative polymerization of azomethine compounds. The oxidative polymerization of these compounds was carried out in a hydrochloric acid aqueous solution using ammonium persulfate as an oxidizing agent, taking into account the heterogeneous flow of the process:

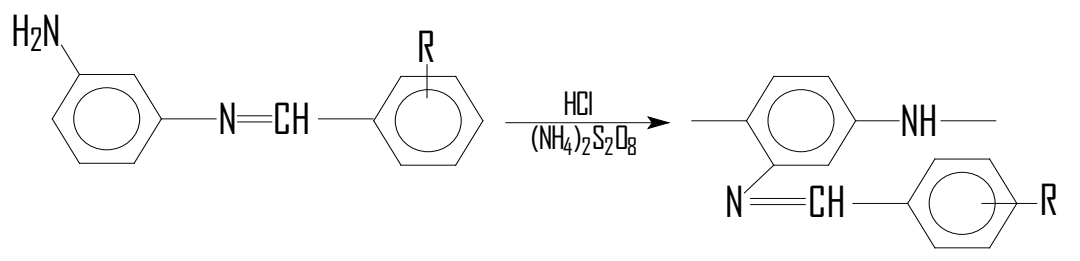

where, $\mathrm{R}=\mathrm{H} ; m-\mathrm{NO}_{2} ; o-\mathrm{NO}_{2} ; p-\mathrm{N}\left(\mathrm{C}_{2} \mathrm{H}_{5}\right)_{2} ; p-\mathrm{OH} ; o-\mathrm{OH}$.

The amount of monomer taken was $4.7 \mathrm{mmol}$, solvent $47 \mathrm{ml}$. $1 \mathrm{M} \mathrm{HCl}$. The amount of initiator is $5.8 \mathrm{mmol}$, previously dissolved in $47 \mathrm{ml}$ of distilled water. The prepared solutions were thermostated for $30 \mathrm{~min}$. and then mixed. The polymerization process monitored with an ionomer of the universal EV-74. At the same time, the $\mathrm{pH}$ of the reaction medium changed every $5 \mathrm{~min}$. until a constant $\mathrm{pH}$ value reached.

In the process of oxidative polymerization of azomethines, the polymers precipitated. The precipitate was filter, washed with $10 \%$ ammonia solution, then with distilled water and dried at a temperature of $40^{\circ} \mathrm{C}$ in a vacuum. The polymers obtained were beige or brown powders soluble in dimethylformamide, $\mathrm{N}$-methylpyrrolidone, dimethylsulfoxide. The reduced viscosity of the synthesized polymers was $0.15-0.25 \mathrm{dl} / \mathrm{g}$. The structure of the obtained polymers was confirmed by IR spectroscopy, where bands were found: $1670-1650 \mathrm{~cm}^{-1}-\mathrm{N}=$ $\mathrm{CH}$ - bond conjugated to the $-\mathrm{C}=\mathrm{C}$ - benzene ring; $1680-1720 \mathrm{~cm}^{-1}$ is the azomethine group $-\mathrm{CH}=\mathrm{N}-$.

For the preliminary determination of the mechanism of oxidative polymerization of azomethines, we have obtained the dependence of $\mathrm{pH}$ on the time in the synthesis of the polymer using 2-amino, 3'-nitrodiphenylamine, which repeats a similar dependence for the polyaniline (Figure 1). 


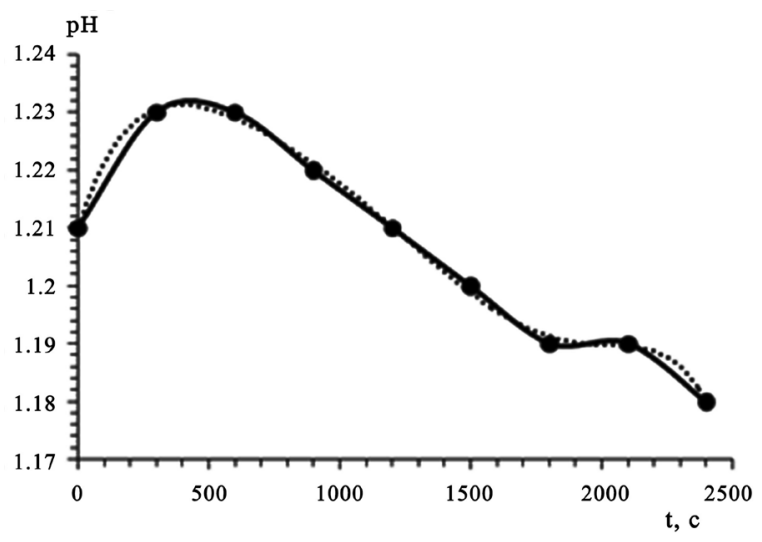

Figure 1. The $\mathrm{pH}$ of the reaction medium as a function of time at a temperature of $20^{\circ} \mathrm{C}$.

Comparison of the dependencies allowed us to assume that the mechanism of oxidative polymerization of 2-amino, 3'-nitrodiphenylazomethine also proceeds through several stages. The first step in the oxidative polymerization of 2-amino, 3'-nitrodiphenylazomethine is a direct one-electron transfer from the monomer molecule to the persulfate ion, to form radical cations that are active centers. The radical cations formed in the first stage are capable of rapid recombination with the release of protons into the reaction system. Consequently, the oxidative polymerization of 2-amino, 3'-nitrodiphenylazomethine involves stages, slow (one-electron transfer), and rapid (recombination of the radical cations).

New azomethines based on $m$-phenylenediamine and substituted benzaldehydes have been obtained, which, when irradiated with UV light, exhibit luminescent properties. It is shown that synthesized azomethines are capable of oxidative polymerization to produce polymers with conjugated systems that can find application as electroactive materials.

\section{Funding}

The work was carried out with the financial support of the State No. 4.5516.2017/8.9.

\section{References}

[1] Novakov, I.A. and Novopoltseva, O.M. (2003) Azomethine: The Practical Application in Chemical Industry and Medicine. Collection of Scientific Articles: Chemistry and Technology of Organoelement Monomers and Polymeric Materials, Volgograd, 3-28.

[2] Liu, G., Chen, Y., Li, R.-W., Zhang, B., Kang, E.-T., Wang, C. and Zhuang, X. (2014) Resistance-Switchable Graphene Oxide-Polymer Nanocomposites for Molecular Electronics. Chem Electro Chem, 1, 514-519.

[3] Ganguly, A., Chakraborty, P., Banerjee, K. and Choudhuri, S.K. (2014) The Role of a Schiff Base Scaffold, N-(2-hydroxy acetophenone) glycinate-in Overcoming Multidrug Resistance in Cancer. European Journal of Pharmaceutical Sciences, 51, 96-109. https://doi.org/10.1016/j.ejps.2013.09.003

[4] Turek, W., Stochmal-Pomarzanska, E., Pron, A. and Haber, J. (2000) Propylene 
Oxidation over Poly(azomethines) Doped with Heteropolyacids. Journal of Catalysis, 189, 297-313. https://doi.org/10.1006/jcat.1999.2678

[5] Novakov, I.A., Novopoltseva, O.M., Tankov, D.Y., Popov, Y.V. and Korchagina, T.K. (2008) Hydroxyl-Containing Azomethine Compounds in the Composition of the Crosslinking Agent of the Copolymer Vinylidene Fluoride with Hexafluoropropylene. News Volgograd Technical University, 39, 112-117.

[6] Borukaev, T.A., Otarova, R.M., Orlov, A.V., Kiseleva, S.G., Karpacheva, G.P. and Malamatov, A.Kh. (2016) New Monomeric Substances-Benzylideneaniline for Oxidative Polymerization. News Kabardino-Balkar State University, 6, 19-23. 